\title{
FV-162 is a novel, orally bioavailable, irreversible proteasome inhibitor with improved pharmacokinetics displaying preclinical efficacy with continuous daily dosing
}

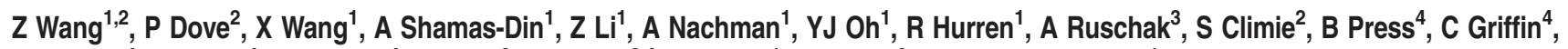 \\ E Undzys ${ }^{4}$, A Aman ${ }^{4}$, R Al-awar ${ }^{4}$, LE Kay ${ }^{3}$, D O'Neill ${ }^{2,4}$, S Trudel ${ }^{1}$, M Slassi ${ }^{2}$ and AD Schimmer,1
}

Approved proteasome inhibitors have advanced the treatment of multiple myeloma but are associated with serious toxicities, poor pharmacokinetics, and most with the inconvenience of intravenous administration. We therefore sought to identify novel orally bioavailable proteasome inhibitors with a continuous daily dosing schedule and improved therapeutic window using a unique drug discovery platform. We employed a fluorine-based medicinal chemistry technology to synthesize 14 novel analogs of epoxyketone-based proteasome inhibitors and screened them for their stability, ability to inhibit the chymotrypsin-like proteasome, and antimyeloma activity in vitro. The tolerability, pharmacokinetics, pharmacodynamic activity, and antimyeloma efficacy of our lead candidate were examined in NOD/SCID mice. We identified a tripeptide epoxyketone, FV-162, as a metabolically stable, potent proteasome inhibitor cytotoxic to human myeloma cell lines and primary myeloma cells. FV-162 had limited toxicity and was well tolerated on a continuous daily dosing schedule. Compared with the benchmark oral irreversible proteasome inhibitor, ONX-0192, FV-162 had a lower peak plasma concentration and longer half-life, resulting in a larger area under the curve (AUC). Oral FV-162 treatment induced rapid, irreversible inhibition of chymotrypsin-like proteasome activity in murine red blood cells and inhibited tumor growth in a myeloma xenograft model. Our data suggest that oral FV-162 with continuous daily dosing schedule displays a favorable safety, efficacy, and pharmacokinetic profile in vivo, identifying it as a promising lead for clinical evaluation in myeloma therapy.

Cell Death and Disease (2015) 6, e1815; doi:10.1038/cddis.2015.187; published online 9 July 2015

The ubiquitin-proteasome system is responsible for the regulation and degradation of the majority of the intracellular proteins in eukaryotic cells. ${ }^{1}$ The $26 \mathrm{~S}$ proteasome is a multisubunit protein complex that mediates the proteolytic degradation and turnover of damaged, misfolded or excess proteins that have been polyubiquitylated in the cytoplasm and nucleus. $^{1,2}$ The $26 \mathrm{~S}$ proteasome consists of a $20 \mathrm{~S}$ core particle, capped by $19 \mathrm{~S}$ regulatory particles.,4 The $19 \mathrm{~S}$ particle participates in the recognition, processing, unfolding, and translocation of ubiquitylated protein substrates into the $20 S$ core. ${ }^{5}$ Substrates are then degraded inside the chamber of the barrel-like $20 \mathrm{~S}$ core particle, where the active sites of multiple $\beta 1, \beta 2$, and $\beta 5$ subunits catalyze caspase-like (C-L), trypsin-like (T-L), or chymotrypsin-like (CT-L) proteolysis, respectively. ${ }^{6,7}$ Inhibition of the $26 \mathrm{~S}$ proteasome activity leads to disruption of the cell cycle and induction of apoptosis. ${ }^{8}$

Cancer cells have an increased dependency on the integrity of the ubiquitin-proteasome system machinery compared with normal cells in preclinical studies. This finding is predominantly evident in hematological malignancies, identifying the
26S proteasome as a promising anticancer therapeutic target. $^{9-12}$ In particular, cells derived from multiple myeloma are notably sensitive to proteasome inhibition, at least in part, owing to their characteristically high rates of immunoglobulin protein biosynthesis and increased proteasome activity. ${ }^{13-15}$ The continuous activity of the proteasome in myeloma cells makes them particularly susceptible to prolonged inhibition. ${ }^{16}$

Bortezomib, the first proteasome inhibitor approved for clinical use, is a dipeptide boronic acid that reversibly binds to the active site of the $\beta 5$ and $\beta 1$ subunit to competitively inhibit proteasome function. ${ }^{9,10,17}$ By inhibiting the proteasome, bortezomib acts through multiple cellular pathways that ultimately result in cell cycle arrest and apoptosis. ${ }^{18}$ Bortezomib is currently approved for the treatment of newly diagnosed, relapsed or refractory multiple myeloma and mantle cell lymphoma. ${ }^{18}$ Carfilzomib was subsequently developed as a second-generation inhibitor that belongs to the epoxyketone class and irreversibly binds to the active site of the $\beta 5$ subunit of the proteasome. Carfilzomib is structurally and mechanistically distinct from bortezomib and overcomes

\footnotetext{
${ }^{1}$ Princess Margaret Cancer Centre, Toronto, ON, Canada; ${ }^{2}$ Fluorinov Pharma Inc., Toronto, ON, Canada; ${ }^{3}$ Department of Molecular Genetics, Biochemistry and Chemistry, University of Toronto, Toronto, ON, Canada and ${ }^{4}$ Ontario Institute for Cancer Research, Toronto, ON, Canada

${ }^{*}$ Corresponding author: AD Schimmer, Princess Margaret Cancer Centre, Room 7-417, 610 University Avenue, Toronto, ON M5G 2M9, Canada. Tel: +1 416 946 2838; Fax: +1 416946 6546; E-mail: aaron.schimmer@utoronto.ca

Abbreviations: C-L, caspase-like; T-L, trypsin-like; CT-L, chymotrypsin-like; NOD/SCID, nonobese diabetic/severe combined immunodeficiency; RBC, red blood cell; MTD, maximum tolerated dose; AUC, area under the curve; $C_{\text {max }}$, peak plasma concentration; $T_{\max }$, time associated with $C_{\text {max }} ; t_{1 / 2}$, terminal half-life; $C L$, clearance; $V_{d}$, volume of distribution

Received 06.3.15; revised 24.4.15; accepted 03.6.15; Edited by Y Shi
} 
<smiles>CC(C)(C)OC(=O)NC(COC(F)F)C(=O)O</smiles><smiles>NC(COC(F)F)C(=O)OCc1ccccc1</smiles><smiles>C1CC[Bi]C1</smiles><smiles>CC(C)(C)OC(=O)NC(COC(F)F)C(=O)NC(COC(F)F)C(=O)OCc1ccccc1</smiles><smiles>CC(C)(C)OC(=O)NC(COC(F)F)C(=O)NC(COC(F)F)C(=O)O</smiles>
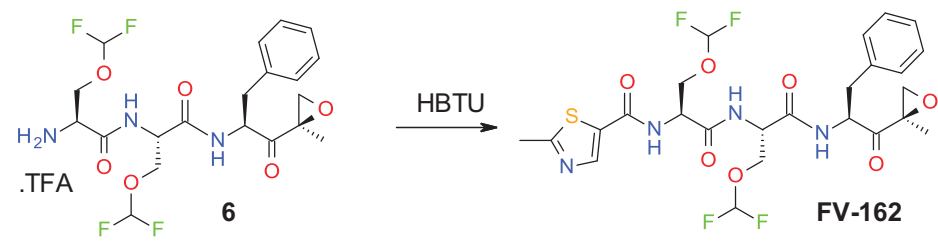

Figure 1 Synthesis of FV-162. FV-162 is a novel structural analog of the irreversible epoxyketone proteasome inhibitors carfilzomib and ONX-0912. It was synthesized in this study using a novel fluorine-based chemistry technology (Fluorinov Pharma Inc., Toronto, ON, Canada). Reaction details and characterizations are given in Materials and Methods

bortezomib resistance in multiple myeloma cell lines and in primary multiple myeloma cells from patients. ${ }^{17,19}$ Carfilzomib is currently also approved for relapsed and refractory multiple myeloma. ONX-0912 (also known as oprozomib) is another epoxyketone class oral proteasome inhibitor that is an analog of carfilzomib. ${ }^{20,21}$ Similar to carfilzomib, ONX-0912 promotes cell death in primary myeloma cells from patients who relapsed after treatment with bortezomib. ${ }^{20}$ ONX-0912 has advanced into phase $\mathrm{I} / \mathrm{II}$ trials in hematological and solid malignancies. ${ }^{22-24}$

Despite their clinical efficacy, treatment with proteasome inhibitors is associated with a number of toxicities, including neuropathy, thrombocytopenia, and cardiotoxicity. ${ }^{25-27}$ The toxicity of currently available proteasome inhibitors necessitates administering the drugs in intermittent dosing schedules, typically biweekly. Although intermittent dosing permits proteasome activity in normal tissues during dose holidays, it has been shown to be sub-optimal for therapy in malignant cells. ${ }^{16}$ Moreover, infrequent administration at relatively high exposures may give rise to undesirable and potentially unnecessary toxicities in normal cells. Potentially, by moderating exposures, an optimized oral proteasome inhibitor with continuous daily dosing could be developed that exploits the high proteasome dependency in malignant cells while sparing normal cells.

In the present study, we report the development of FV-162, a novel, metabolically stable and orally bioavailable epoxyketone-based proteasome inhibitor. FV-162 displays potent anticancer activity and maintains a wide differential activity between malignant and normal cells despite a continuous daily dosing schedule in multiple myeloma cell lines, primary patient cells, and animal models. Overall, our results show that FV-162 inhibits the proteasome, displays metabolic stability, and has a favorable toxicity profile.

\section{Results}

Synthesis and identification of a novel proteasome inhibitor, FV-162. To identify novel orally bioavailable proteasome inhibitors with improved pharmacokinetics and toxicity, we applied a unique fluorine-based medicinal chemistry platform to design and synthesize a diverse set of tripeptide and tetrapeptide epoxyketones, using the structures of ONX-0912 and carfilzomib as chemical backbones. The incorporation of difluoromethoxy moieties into the chemical scaffolds was aimed to improve metabolic stability, decrease toxicity, and increase oral bioavailability by increasing drug exposure (area under the curve (AUC)), whereas lowering the peak plasma concentration $\left(C_{\max }\right)$ and prolonging half-life $t_{1 / 2} \cdot{ }^{28}$ Of the 14 unique structural analogs evaluated (Supplementary Figure S1), FV-162 was the lead compound based on potency in proteasome inhibition and cell viability assays (Supplementary Figure S2). Therefore, we focused on FV-162 and compared its activity with the orally bioavailable irreversible proteasome inhibitor, ONX-0912. The methodology of synthesis and the structure of FV-162 are outlined in Figure 1.

FV-162 is a metabolically stable proteasome inhibitor with potent antimyeloma activity. To assess the metabolic stability of FV-162, we incubated the compound with mouse liver microsomes. The percentage of parent compound remaining after $15 \mathrm{~min}$ was measured by liquid chromatography/mass spectroscopy (LC/MS) as an indicator of metabolic stability. Over $80 \%$ of FV-162 remained intact after incubation with liver microsomes. This was similar to the stability of carfilzomib at $70 \%$ (Supplementary Figure S2A) and higher than the stability of ONX-0912 at 56\% (Figure 2a).

Consistent with its design as a proteasome inhibitor, FV-162 inhibited the enzymatic activity of the CT-L proteasome subunit when added to total cell lysates from 10 different human myeloma cells. The $\mathrm{IC}_{50}$ values of $\mathrm{FV}-162$ were lower than $60 \mathrm{nM}$ for all the cell lines tested. In 6 of the 10 cell lines, FV-162 was over five times more potent than ONX-0912 (Figure $2 b$ ). Consistent with its ability to inhibit the proteasome, FV-162 decreased cell growth and viability in all the 10 human myeloma cell lines as measured by 3-(4,5dimethylthiazol-2-yl)-5-(3-carboxymethoxyphenyl)-2-(4-sulfophenyl)-2H-tetrazolium (MTS) assay. In 5 of the 10 cell lines, FV-162 was over two times more potent than ONX-0912 


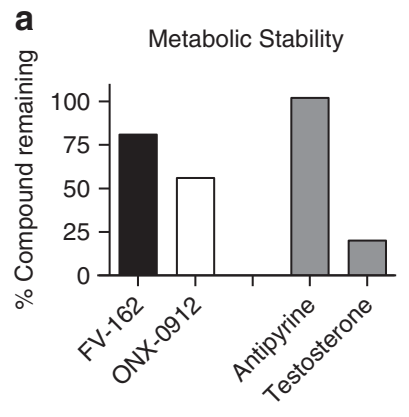

b CT-L Proteosome Inhibition

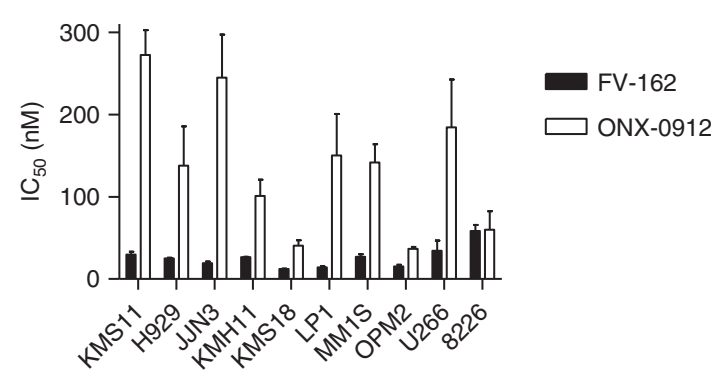

C

Cell Viability

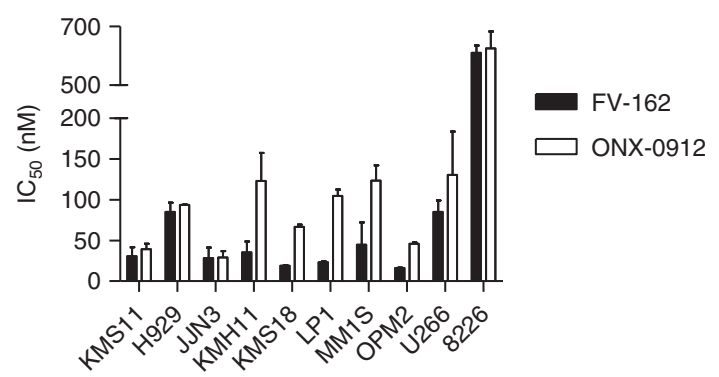

Figure 2 FV-162 is a novel proteasome inhibitor with potent antimyeloma activity. (a) The metabolic stability of the compounds shown was determined in the presence of pooled mouse liver microsomes. The percentage of $5 \mu \mathrm{M}$ of each compound remaining after an incubation of $15 \mathrm{~min}$ with $0.5 \mathrm{mg} / \mathrm{ml}$ liver microsomes was detected by LC/MS. Antipyrine and testosterone ( $5 \mu \mathrm{M}$ each) were included as positive and negative controls, respectively (gray bars). One representative experiment is shown. (b) CT-L proteasome activity present in indicated whole cell lysates of 10 human myeloma cell lines was determined through specific cleavage of the fluorogenic substrate Suc-Leu-Leu-Val-Tyr-AMC following exposure to each compound for $2 \mathrm{~h}$. Sensitivity was evaluated using the half-maximal inhibitory concentration (IC 50$)$. (mean \pm S.D., $n=3$ ). (c) Cell growth and viability of 10 human myeloma cell lines was assessed using the MTS assay after exposure to each compound for $72 \mathrm{~h}$. Sensitivity was evaluated using the IC $\mathrm{C}_{50}$. (mean \pm S.D. $n=3$ )

(Figure 2c). Cell death was independently confirmed by trypan blue staining (data not shown).

Finally, we examined the preclinical efficacy of FV-162 in primary myeloma patient samples. Mononuclear cells isolated from the bone marrow of eight multiple myeloma patients were treated with FV-162 or ONX-0912 for $48 \mathrm{~h}$. After treatment, the percentage of viable myeloma $\left(\mathrm{CD} 138^{+}\right)$and normal hematopoietic (CD138 ${ }^{-}$) cells was measured by flow cytometry by staining with Annexin V. At least $80 \%$ of primary myeloma cells were killed by FV-162 at concentrations $\leqslant 0.1 \mu \mathrm{M}$ while normal hematopoietic cells were largely insensitive (Figure 3a). At a five-fold higher concentration of $0.5 \mu \mathrm{M}$, FV-162 was toxic to $50 \%$ of $\mathrm{CD} 138^{-}$cells. In contrast, similar concentrations of ONX-0912 were less effective at inducing death in primary myeloma cells but had no adverse effects on CD138- cells (Figure 3b).

Pharmacokinetics of FV-162 in rodents. We hypothesized that stabilization of the epoxyketone backbone might improve pharmacokinetic profile and therapeutic index in vivo of FV-162. Therefore, we evaluated the pharmacokinetics of FV-162 in comparison with the benchmark inhibitor ONX-0912 in non-obese diabetic/severe combined immunodeficient (NOD/SCID) mice and Sprague-Dawley rats after oral and intravenous administration. Following oral $(25 \mathrm{mg} / \mathrm{kg})$ administration in mice, FV-162 demonstrated greater than three-fold higher oral bioavailability and a six-fold increase in drug exposure (AUC; 3117 versus $513 \mathrm{~min} \times \mathrm{ng} / \mathrm{ml}$ ) relative to that of oral ONX-0912. In contrast, FV-162 displayed an almost two-fold decrease in $C_{\max }$ than that of ONX-0912 (21 versus $38 \mathrm{ng} / \mathrm{ml}$ ) (Figure $4 \mathrm{a}$ ). Following intravenous (5 mg/kg) administration, FV-162 similarly exhibited more than a four-fold increase in its $t_{1 / 2}$ (95 versus $22 \mathrm{~min}$ ) and a two-fold increase in drug exposure (AUC; 6633 versus 3248 $\min \times \mathrm{ng} / \mathrm{ml}$ ) compared with ONX-0912 (Table 1).

The pharmacokinetic profiles of FV-162 and ONX-0912 following oral administration $(40 \mathrm{mg} / \mathrm{kg}$ ) in rats were similar to mice. FV-162 achieved a greater drug exposure (AUC; 27073 versus $22627 \mathrm{~min} \times \mathrm{mg} / \mathrm{ml}$ ) and a lower $C_{\max }$ (615 versus $1273 \mathrm{mg} / \mathrm{ml}$ ) compared with ONX-0912 (Figure 4b). Following intravenous $(5 \mathrm{mg} / \mathrm{kg})$ administration, FV-162 exhibited an almost seven-fold increase in its $t_{1 / 2}$ (68 versus $10 \mathrm{~min}$ ) and close to a three-fold decrease in $C_{\max }(392$ versus $1094 \mathrm{ng} / \mathrm{ml}$ ), relative to ONX-0912 (Table 1).

Oral FV-162 displays antimyeloma activity in a xenograft model. To characterize the preliminary safety profile of FV-162, mice were treated with $30 \mathrm{mg} / \mathrm{kg}$ of the drug by oral gavage. Mice treated with FV-162 displayed no evidence of toxicity, behavioral change, or loss of body weight for up to 8 days of treatment. In contrast, daily dosing of ONX-0912 resulted in loss of body weight (Figure 5a). The single maximum tolerated dose (MTD) of FV-162 was $200 \mathrm{mg} / \mathrm{kg}$ and that of ONX-0912 was $40 \mathrm{mg} / \mathrm{kg}$ by oral gavage in mice.

We next evaluated the safety profile and anticancer efficacy in a subcutaneous xenograft model using the MM.1S human 
a

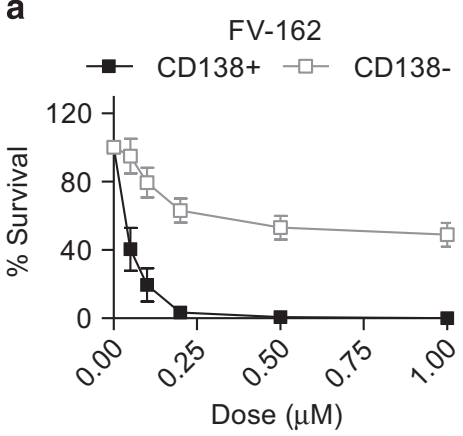

b

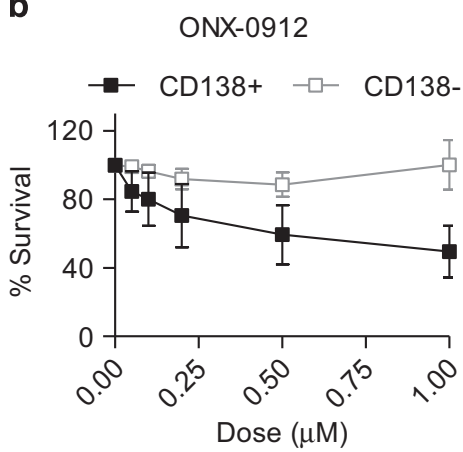

Figure 3 FV-162 selectively induces cell death in primary human myeloma cells. The effects of (a) FV-162 and (b) ONX-0912 on the viability of primary mononuclear cells isolated from the bone marrow of patients with multiple myeloma. Survival was calculated by detecting Annexin V staining and flow cytometry following $48 \mathrm{~h}$ of treatment, relative to vehicle control. FV-162 selectively reduced the viability of primary $\mathrm{CD}_{138^{+}}$myeloma cells over $\mathrm{CD} 138^{-}$normal hematopoietic cells. (mean \pm S.E.M., $n=8$ )
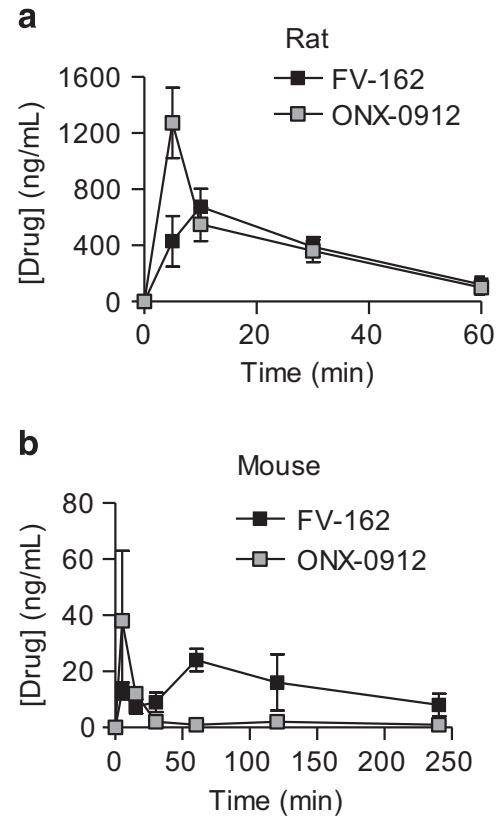

Figure 4 Oral FV-162 displays superior pharmacokinetics compared with ONX-0912. Pharmacokinetics of FV-162 and ONX-0912 in (a) rats $(40 \mathrm{mg} / \mathrm{kg})$ and (b) mice $(25 \mathrm{mg} / \mathrm{kg})$ following oral administration. Rodents were administered with FV-162 or ONX-0912, and plasma was collected at increasing times after treatment. Plasma concentration of the two drugs was determined using HPLC. Mean \pm S.D. plasma levels are shown $(n=3)$
Table 1 Pharmacokinetics of FV-162 and ONX-0912 in mice and rats following intravenous or oral administration

\begin{tabular}{|c|c|c|c|c|}
\hline \multirow{2}{*}{$\begin{array}{l}\text { Pharmacokinetic } \\
\text { parameter }\end{array}$} & \multicolumn{2}{|c|}{ FV-162 } & \multicolumn{2}{|c|}{ ONX-0912 } \\
\hline & $5 \mathrm{mg} / \mathrm{kg}$ & $\begin{array}{c}25 \mathrm{mg} / \mathrm{kg} \\
\text { p.o. }\end{array}$ & $\underset{\text { i.v. }}{5 \mathrm{mg} / \mathrm{kg}}$ & $\begin{array}{c}25 \mathrm{mg} / \mathrm{kg} \\
\text { p.o. }\end{array}$ \\
\hline \multicolumn{5}{|l|}{ Mouse } \\
\hline$C_{\max }, \mathrm{ng} / \mathrm{ml}$ & 268 & 21 & 187 & 38 \\
\hline$T_{\max }, \min$ & 5 & 60 & 5 & 5 \\
\hline AUC, $\min \times n g / m l$ & 6633 & 3117 & 3248 & 513 \\
\hline$t_{1 / 2}, \min$ & 95 & $N D$ & 22 & $N D$ \\
\hline $\mathrm{CL}, \mathrm{ml} / \mathrm{min} / \mathrm{kg}$ & 702 & $N D$ & 1489 & $N D$ \\
\hline$V_{\mathrm{d}}, \mathrm{l} / \mathrm{kg}$ & 96 & $N D$ & 48 & $N D$ \\
\hline $\mathrm{F}, \%$ & NA & 10 & NA & 3 \\
\hline \multirow{2}{*}{$\begin{array}{l}\text { Pharmacokinetic } \\
\text { parameter }\end{array}$} & \multicolumn{2}{|c|}{ FV-162 } & \multicolumn{2}{|c|}{ ONX-0912 } \\
\hline & $\begin{array}{l}5 \mathrm{mg} / \mathrm{kg} \\
\text { i.v. }\end{array}$ & $\begin{array}{l}40 \mathrm{mg} / \mathrm{kg} \\
\text { p.o. }\end{array}$ & $\underset{\text { i.v. }}{5 \mathrm{mg} / \mathrm{kg}}$ & $\begin{array}{c}40 \mathrm{mg} / \mathrm{kg} \\
\text { p.o. }\end{array}$ \\
\hline \multicolumn{5}{|l|}{ Rat } \\
\hline$C_{\max }, \mathrm{ng} / \mathrm{ml}$ & 392 & 615 & 1094 & 1273 \\
\hline$T_{\max }, \min$ & 5 & 15 & 5 & 5 \\
\hline AUC, $\min \times n g / m l$ & 24184 & 27073 & 18070 & 22627 \\
\hline$t_{1 / 2}, \min$ & 68 & ND & 10 & ND \\
\hline $\mathrm{CL}, \mathrm{ml} / \mathrm{min} / \mathrm{kg}$ & 1345 & ND & 273 & ND \\
\hline$V_{\mathrm{d}}, \mathrm{l} / \mathrm{kg}$ & 20 & ND & 4 & ND \\
\hline$F, \%$ & NA & 14 & NA & 16 \\
\hline
\end{tabular}

Abbreviations: i.v., intravenous; NA, not applicable; ND, not determined; p.o., oral

myeloma cells. Mice with established tumors were treated with FV-162 at 30 and $100 \mathrm{mg} / \mathrm{kg}$ daily or with ONX-0912 at $30 \mathrm{mg} / \mathrm{kg}$ administered twice weekly by oral gavage similar to a previously described schedule for this drug. ${ }^{20}$ All three schedules of proteasome inhibitors significantly reduced tumor burden compared with the vehicle control by 24 days after xenograft inoculation $(P<0.01)$, reaching greater statistical significance after 27 days $(P<0.001)$. Daily administration of FV-162 at half of its MTD $(100 \mathrm{mg} / \mathrm{kg})$ produced a greater reduction in tumor growth by 27 days after xenograft inoculation compared with ONX-0912 at close to its MTD (30 mg/kg) $(P<0.05$; Figure 5b). Tumor reduction after treatment with FV-162 was similar to the effect of carfilzomib (Supplementary Figure S3). All of the regimens tested were well tolerated by the mice, with no substantial effect on mouse body weight observed during treatment (Figure 5c). Thus FV-162 is well tolerated and displays preclinical efficacy with continuous daily dosing with a wide differential activity between malignant and normal cells.

Oral FV-162 displays pharmacodynamic activity in mice at tolerable doses. We then compared the ability of FV-162 and ONX-0912 to inhibit the CT-L enzymatic activity in isolated red cells after oral administration to mice. Mice were treated with a single dose of oral ONX-0912 (30 mg/kg) or FV-162 (30 and $100 \mathrm{mg} / \mathrm{kg}$ ). CT-L proteasome activity was measured in red blood cells (RBCs) isolated from the mice up to $24 \mathrm{~h}$ postdose (Figure $5 \mathrm{~d}$ ). At equivalent doses $(30 \mathrm{mg} / \mathrm{kg}$ ), FV-162 produced less inhibition of the CT-L activity than ONX-0912. At half the MTD $(100 \mathrm{mg} / \mathrm{kg}), \mathrm{FV}-162$ performed similarly to almost the MTD of ONX-0912 (30 mg/kg). We also demonstrated that inhibition of proteasome activity in the isolated RBCs was sustained for up to $24 \mathrm{~h}$ after treatment with either FV-162 or ONX-0912. In contrast, proteasome 


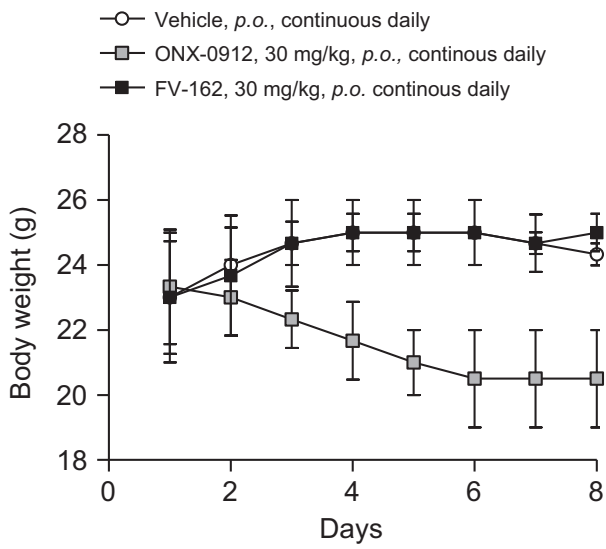

C

- - Vehicle, p.o., continuous daily $\times 3$ weeks

$\neg-$ ONX-0912, $30 \mathrm{mg} / \mathrm{kg}$, p.o., days 1,2/wk $\times 3$ weeks

$\rightarrow-\mathrm{FV}-162,30 \mathrm{mg} / \mathrm{kg}$, p.o., continuous daily $\times 3$ weeks

$\longrightarrow$ FV-162, $100 \mathrm{mg} / \mathrm{kg}$, p.o., continuous daily $\times 3$ weeks
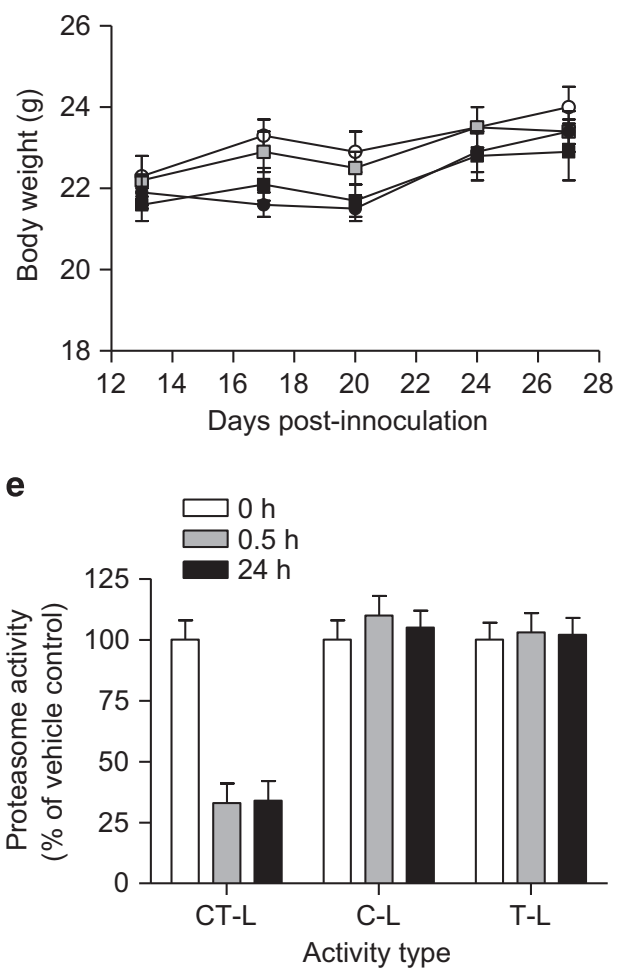

b

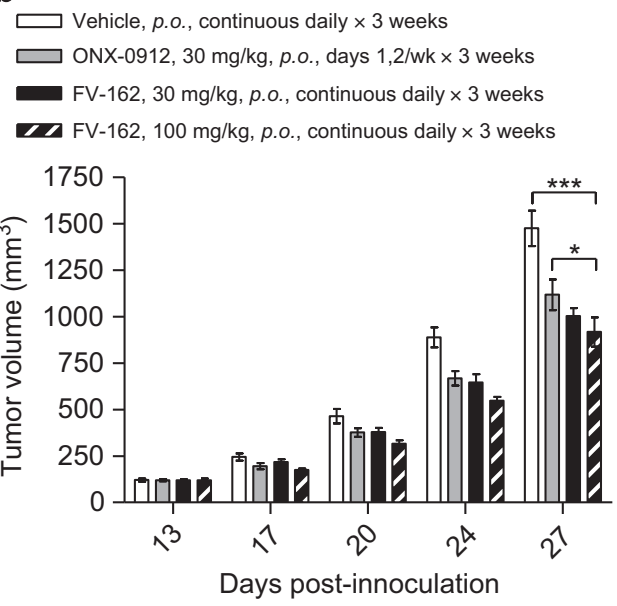

d

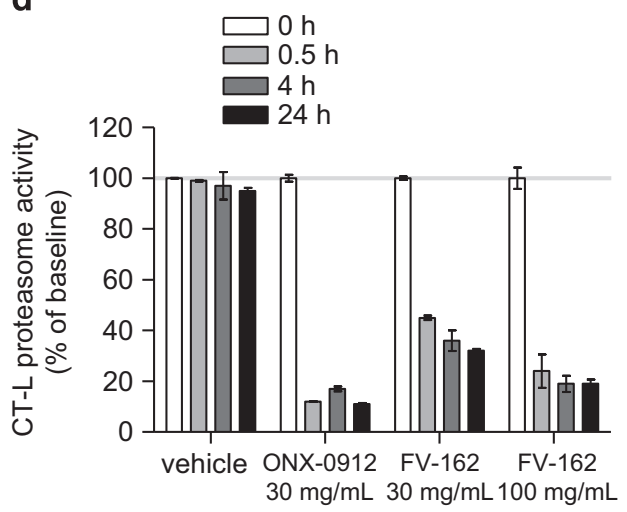

Figure 5 FV-162 displays pharmacodynamic and antimyeloma activity at tolerable doses in mice. (a) NOD/SCID mice were treated with FV-162 (30 mg/kg), ONX-0912 (30 mg/kg), or vehicle control (5\% DMSO, 20\% Cremophor) daily, and body weight was monitored for up to 8 days. Mean \pm S.E.M., $n=3$. (b and c) NOD/SCID mice were injected subcutaneously with $5 \times 10^{6}$ cells from the human MM.1S myeloma cell line. Thirteen days after injection, mice were treated with FV-162 ( 30 , 100 mg/kg by oral gavage), ONX-0912 (30 mg/kg by oral gavage), or vehicle (5\% DMSO, 20\% Cremophor) on the indicated schedule. Tumor volume (b) and body weight (c) were monitored over time. Mean \pm S.E.M., $n=10$. ${ }^{*} P<0.05$ and ${ }^{* *} P<0.001$ from a two-way ANOVA with Bonferroni posttests comparing all treatment groups at day 27 . (d) NOD/SCID mice were treated with ONX-0912 (30 mg/kg by oral gavage), FV-162 (30, $100 \mathrm{mg} / \mathrm{kg}$ by oral gavage), or vehicle control (5\% DMSO, 20\% Cremophor). Lysates were prepared from RBCs at different time points (up to $24 \mathrm{~h}$ ) after drug treatment, and CT-L proteasome activity was tested. Mean \pm S.D., $n=3$. (e) Lysates prepared from the RBCs at different time points from NON/SCID mice treated with FV-162 (30 mg/ml) were tested for C-L, T-L, and/or CT-L proteasome activity. Mean \pm S.D., $n=3$

activity recovered to $>50 \%$ of baseline levels by $24 \mathrm{~h}$ after treatment with the reversible inhibitor bortezomib (data not shown). In contrast to the effects on the CT-L proteasome inhibition in murine RBCs, administration of FV-162 did not inhibit $\mathrm{C}-\mathrm{L}$ or on $\mathrm{T}-\mathrm{L}$ subunit activity in murine $\mathrm{RBC}$ (Figure 5e). Taken together, these data indicate that that FV-162 is an orally bioavailable, selective proteasome inhibitor with a favorable ratio of efficacy to toxicity. 


\section{Discussion}

The proteasome inhibitors bortezomib and carfilzomib produce clinical responses in hematological malignancies, such as multiple myeloma and mantle cell lymphoma. Although prolonged proteasome inhibition has been shown to be the most optimal antimyeloma therapy in preclinical models, ${ }^{16}$ toxicity restricts dose intensity of these compounds in the clinical setting. Compared with bortezomib, more selective epoxyketone-based proteasome inhibitors should be capable of prolonged target inhibition by avoiding boronic-acid-based off-target toxicity. ${ }^{16}$ However, first-generation epoxyketone inhibitors such as carfilzomib and ONX-0912 have poor pharmacokinetics, are administered at MTD, and are also associated with severe toxicities. Therefore, selective proteasome inhibitors with optimized pharmacokinetics may achieve similar or even prolonged target inhibition with reduced toxicity. Chemical optimization of this class of therapeutics may lead to an improved therapeutic window.

By testing a panel of fluorinated derivatives of the epoxyketone proteasome inhibitors ONX-0912 and carfilzomib, we identified FV-162 as a novel and orally bioavailable proteasome inhibitor. FV-162 has an improved pharmacokinetic profile that was associated with comparable efficacy and improved safety profile. In studies of rodents, FV-162 had a lower $C_{\max }$ and higher AUC than ONX-0912 after the administration of an equivalent oral dose. Despite the total greater exposure to the drug, FV-162 was better tolerated in mice xenograft models and displayed a wider differential activity between malignant and normal cells. These results are consistent with previous studies demonstrating that toxicity of irreversible proteasome inhibitors is related more closely to $C_{\max }$ than the AUC. For example, Yang et al. ${ }^{29}$ studied the pharmacokinetics and toxicity of bolus and 30 minute infusions of carfilzomib in rats. At a dose of $8 \mathrm{mg} / \mathrm{kg}$, a bolus infusion of carfilzomib was lethal to $44 \%$ of rats, whereas the same dose given over 30 min was not toxic. ${ }^{29}$ Recent human data also support the relationship between the $C_{\max }$ of epoxyketone inhibitors and toxicity. Patients with multiple myeloma tolerated up to $56 \mathrm{mg} / \mathrm{m}^{2}$ carfilzomib without adverse effects when the drug was given as an infusion over $30 \mathrm{~min}$, which is more than double the MTD of carfilzomib when given as a bolus infusion. ${ }^{30}$ Thus increasing the stability and AUC of epoxyketone-based proteasome inhibitors may reduce the need for high instantaneous exposures and concomitant $C_{\max }$ toxicities.

In vitro metabolism studies demonstrated that FV-162 had comparable stability to carfilzomib and greater stability than ONX-0912. Furthermore, a daily dose of FV-162 reduced the tumor volume without a loss in weight in the mouse xenograft model. However, in isolated red blood cells from mice, a single low oral dose of FV-162 produced incomplete inhibition of the proteasome. Taken together, these data suggest that partial inhibition of the proteasome may be sufficient to eradicate malignant cells but spare normal cells. As such, we hypothesize that the proteasome complex operates at near maximal capacity in myeloma and partial inhibition of this complex is cytotoxic to myeloma cells. In contrast, the proteasome complex functions at submaximal capacity in normal cells and has greater reserve to tolerate partial inhibition. Future studies should test this hypothesis by examining the biological capacity of the proteasome complex.

Increased expression of the immunoproteasome subunit $\beta 5 \mathrm{i}$ renders leukemia and myeloma cells more sensitive to proteasome inhibitors, including bortezomib, carfilzomib, and ONX-0912. ${ }^{31,32}$ Future studies should therefore examine the differential ability of FV-162 and ONX-0912 to inhibit components of the immunoproteasome as well as the constitutive proteasome.

Currently, ONX-0912 is being evaluated in phase 1 and 2 clinical trials, alone and in combination with dexamethasone and sorafenib for hematological malignancies and solid tumors. In a phase 1 study of once-daily orally administered ONX-0912 in patients with advanced refractory or recurrent solid tumors, the MTD was $150 \mathrm{mg} / \mathrm{day}^{23,24}$ When administered twice daily, the MTD has not been reached at cumulative doses up to $190 \mathrm{mg} /$ day. The most commonly treated side effects were gastrointestinal related and thrombocytopenia. ${ }^{23}$ ${ }^{24}$ To date, responses have not been reported.

In summary, we have identified a novel proteasome inhibitor FV-162 that has favorable pharmacokinetic and safety profiles for improved dose intensity. Continuous daily dosing of FV-162 well below its MTD appears more optimal for exploiting the proteasome dependency of malignant cells while minimizing toxicities. Thus, given the advantages of FV-162 observed in this study, clinical investigation of this promising agent is warranted.

\section{Materials and Methods}

Compounds and reagents. All proteasome inhibitors except bortezomib were synthesized and provided by Fluorinov Pharma, Inc. (Toronto, ON, Canada). Bortezomib was purchased from Millennium Pharmaceuticals, Inc. (Cambridge, MA, USA). Fluorogenic proteasome substrates were obtained from Enzo Life Sciences (Plymouth Meeting, MA, USA). Compounds and proteasome substrates were dissolved in dimethyl sulfoxide (DMSO) to stock concentrations of 10 and $2 \mathrm{mM}$, respectively, and stored at $-20^{\circ} \mathrm{C}$.

Synthesis of FV-162. FV-162 was synthesized by initially coupling fluorinated serine derivatives 1 and 2 (Figure 1) by using HBTU to give a boc/benzyl-protected dipeptide, 3 . This was hydrogenated to remove the benzyl group and the resulting carboxylic acid was coupled with an epoxyketone derivative of phenylalanine to give compound 5. The boc-protecting group was then cleaved using TFA and DCM giving compound 6 as a trifluoroacetate salt, which was, in turn, coupled with 2methylthiazole-5-carboxylic acid (using HBTU) to give the desired product, FV-162.

Cells and cell culture. Human multiple myeloma cell lines 8226, H929, JJN3, KMH11, KMS11, KMS18, LP1, MM.1 S, OPM2, and U266 were grown in Iscove's modified Dulbecco's medium (IMDM). Cell lines were authenticated with short tandem repeat method in September 2011. In addition, cell lines were continually monitored by morphological inspection. Primary mononuclear cells were isolated from peripheral blood or bone marrow samples from multiple myeloma patients at the Princess Margaret Cancer Centre (Toronto, ON, Canada) by Ficoll density gradient centrifugation and cultured in IMDM. All cell culture media were obtained from the Ontario Cancer Institute Tissue Culture Media Facility (Toronto, ON, Canada) and were supplemented with $10 \%$ fetal calf serum, $100 \mu \mathrm{g} / \mathrm{ml}$ penicillin, and $100 \mu \mathrm{g} / \mathrm{ml}$ streptomycin (Hyclone, Logan, UT, USA). All cells were grown in a humidified incubator at $37^{\circ} \mathrm{C}$ with $5 \% \mathrm{CO}_{2}$.

Metabolic stability assay. Pooled liver microsomes isolated from male CD-1 mice were purchased from BD Biosciences (San Jose, CA, USA). Metabolic stability was calculated by measuring the percentage of $5 \mu \mathrm{M}$ of each test compound remaining after $15 \mathrm{~min}$ incubation with $0.5 \mathrm{mg} / \mathrm{ml}$ liver microsomes at $37^{\circ} \mathrm{C}$. Compounds were detected by LC/MS using a Xevo quadrupole time-of-flight mass 
spectrometer and an ACQUITY ultra-performance LC (UPLC) system (Waters Inc., Milford, MA, USA) to determine relative peak areas of each parent compound.

Cell viability assays. Cellular viability was primarily assessed by MTS assay according to the manufacturer's instructions (Promega, Madison, WI, USA). Ten thousand cells per well were seeded in triplicate in tissue culture-treated 96-well plates. Two hours after seeding, cells were treated with proteasome inhibitors for $72 \mathrm{~h}(0.01-10 \mu \mathrm{M})$ or DMSO vehicle control. Cell viability was independently confirmed by reading the optical density at $490 \mathrm{~nm}$ and by exclusion of trypan blue stain (Invitrogen, Burlington, ON, Canada). Viability of primary mononuclear cells was determined by Annexin $\mathrm{V}$-fluorescein isothiocyanate and propidium iodide costaining (Biovision Research Products, Mountain View, CA, USA) using flow cytometry according to the manufacturer's instructions after $48 \mathrm{~h}$ of treatment with inhibitors or vehicle control.

\section{Proteasome activity assays}

Cell lysates: Cells were harvested by centrifugation at 1200 r.p.m. at room temperature. Cell pellets were washed with PBS and lysed with assay lysis buffer (50 mM HEPES (2-[4-(2-hydroxyethyl) piperazin-1-yl]]ethanesulfonic acid)), pH 7.5; $150 \mathrm{mM} \mathrm{NaCl} ; 1 \%$ Triton X-100; 2 mM ATP). Cell lysates were incubated on ice for $30 \mathrm{~min}$, mixed by vortex every $5 \mathrm{~min}$, and centrifuged at $12000 \times \mathrm{g}$ for $10 \mathrm{~min}$. Supernatants were transferred to a 96-well plate in triplicate. For each assay, $10 \mu \mathrm{g}$ of total protein were incubated for $1 \mathrm{~h}$ at $37^{\circ} \mathrm{C}$ with increasing concentrations $(0.001-10 \mu \mathrm{M})$ of test compound or vehicle control diluted in assay buffer $(50 \mathrm{mM}$ Tris- $\mathrm{HCl}$ (tris(hydroxymethyl)aminomethane- $\mathrm{HCl}$ ), pH 7.5; $150 \mathrm{mM} \mathrm{NaCl).} \mathrm{After}$ incubation, a specific fluorogenic proteasome substrate was added to each assay reaction ( $40 \mu \mathrm{M}$ in a total volume of $100 \mu \mathrm{l})$. N-Succinyl-Leu-Leu-Val-Tyr-7-amino-4methylcoumarin (Suc-Leu-Leu-Val-Tyr-AMC) was used for measuring CT-L activity, t-butoxycarbonyl- Leu-Arg-Arg-7-amino-4-methylcoumarin (Boc-Leu-Arg-Arg-AMC) for T-L activity, and benzyloxycarbonyl-L-leucyl-L-leucyl-L-glutamyl-7-amino-4methylcoumarin (Z-Leu-Leu-Glu-AMC) for C-L activity. The excitation wavelength was $360 \mathrm{~nm}$ and the fluorescence emission of free AMC released during the enzymatic reaction was detected at $460 \mathrm{~nm}$ on a SpectraMax M5 fluorescent spectrophotometric plate reader (Molecular Devices, Sunnyvale, CA, USA). AMC release rate was measured at $37^{\circ} \mathrm{C}$ in a kinetic mode, recording every $5 \mathrm{~min}$ for $30 \mathrm{~min}$.

Murine red blood cells: Five-to-six-week-old male NOD/SCID mice were administered vehicle (5\% DMSO, $20 \%$ Cremophor) or proteasome inhibitors either intravenously or by oral gavage ( 3 mice per group), and 20-50 $\mu$ l of venous blood were collected from each mouse over $24 \mathrm{~h}$. Blood samples were mixed with heparin (APP Pharmaceuticals; Schaumburg, IL, USA) in $0.5-\mathrm{ml}$ tubes in accordance with the manufacturer's instructions. After centrifugal separation at $3000 \times \mathrm{g}$ for $10 \mathrm{~min}$, RBCs in the bottom layer were transferred into a new tube and stored at $-70^{\circ} \mathrm{C}$ until use. RBCs were lysed with assay lysis buffer and incubated on ice for $30 \mathrm{~min}$, mixing by vortex every $5 \mathrm{~min}$, and centrifuged at $12000 \times \mathrm{g}$ for $10 \mathrm{~min}$. Supernatants were transferred to a 96-well plate and proteasome activity was measured as described in 'Cell lysates' section.

Dose tolerance studies. NOD/SCID mice were administered FV-162 (30 mg/kg daily, 7 days/week) in a 5\% DMSO, 20\% Cremophor vehicle by oral gavage or ONX-0912 (30 mg/kg daily, 7 days/week) in a $5 \%$ DMSO, $20 \%$ Cremophor vehicle by oral gavage for a week. Mice were monitored for changes in body weight, behavior, and physical appearance.

Pharmacokinetic studies. NOD/SCID mice were administered FV-162 or ONX-0912 at doses of $5 \mathrm{mg} / \mathrm{kg}$ intravenously or $25 \mathrm{mg} / \mathrm{kg}$ by oral gavage in a $12.5 \%$ ethanol, $12.5 \%$ Tween-80 vehicle (3 mice per group). Venous blood samples $(20-50 \mu \mathrm{l})$ were collected at $5,15,30 \mathrm{~min}$, and 1,2 , and $4 \mathrm{~h}$ postdose. Plasma was separated from whole blood by centrifugation and stored at $-20^{\circ} \mathrm{C}$ until analysis. Male Sprague-Dawley rats were administered FV-162 or ONX-0912 at doses of $5 \mathrm{mg} / \mathrm{kg}$ intravenously or $40 \mathrm{mg} / \mathrm{kg}$ by oral gavage in a $12.5 \%$ ethanol, $12.5 \%$ Tween-80 vehicle ( 3 rats per group). Venous blood samples $(20-50 \mu l)$ were collected at 5, 10,30, and 60 min postdose. Plasma was separated from whole blood by centrifugation and stored at $-20^{\circ} \mathrm{C}$ until analysis. The $C_{\max }$, its associated time $\left(T_{\max }\right)$, the terminal half-life $\left(t_{1 / 2}\right)$, area under the plasma concentration-time curve $(A \cup C)$, clearance $(C L)$, and volume of distribution $\left(V_{d}\right)$ were evaluated using Pheonix WinNonlin 6.2.1 (Princeton, NJ, USA), and relative oral bioavailability $(F \%)$ values were calculated as follows: $F \%=A U C_{\text {oral }}$ gavage $\mathrm{AUC}_{\text {intravenous }} \times 100$

Efficacy in xenograft model. Human MM.1S myeloma cells $\left(5 \times 10^{6}\right)$ were injected subcutaneously into 6-8-week-old female NOD/SCID mice (10 mice per group). When tumors were palpable, mice were administered vehicle by oral gavage (5\% DMSO, 20\% Cremophor; once daily $\times 3$ weeks), carfilzomib intravenously $(5 \mathrm{mg} / \mathrm{kg}$, once daily on days 1 and 2 of each week $\times 3$ weeks), ONX-0912 by oral gavage ( $30 \mathrm{mg} / \mathrm{kg}$, once daily on days 1 and 2 of each week $\times 3$ weeks), or FV-162 by oral gavage ( $30 \mathrm{mg} / \mathrm{kg}$ or $100 \mathrm{mg} / \mathrm{kg}$, once daily $\times 3$ weeks). Over time, tumor volume (tumor length $\times$ width $^{2} \times 0.5236$ ) was measured with calipers (Control Company, Friendswood, TX, USA), and mouse body weight was monitored.

Statistics. Unless otherwise indicated, all experiments have been performed independently at least three times. Half-maximal inhibitory concentration $\left(\mathrm{IC}_{50}\right)$ values were calculated using Sigmaplot 8.0 (SPSS Inc., Chicago, IL, USA), computing a four-parameter logistic equation from inhibition curves. Total drug exposure in mice and $C_{\max }$ in rats was compared using an unpaired $t$-test. Inhibitor efficacy in the myeloma xenograft model was compared using a two-way ANOVA with Bonferroni posttests comparing all treatment conditions.

Study approvals. All mouse experiments were performed in accordance with approval from the Ontario Cancer Institute Animal Care Committee or the approval for the CRO. The collection and use of human tissue was approved by the University Health Network Research Ethics Board, and samples were obtained with informed consent.

\section{Conflict of Interest}

PD, SC, DON, and MS are employees of Fluorinov Pharma Inc. ZW has received funding from Fluorinov Pharma Inc. ADS is an advisory board member of Fluorinov Pharma Inc. All other authors declare no conflict of interest.

Acknowledgements. This work was supported by the Leukemia and Lymphoma Society. ADS holds the Barbara Baker Chair Leukemia Research. This research is partially sponsored by Fluorinov Pharma Inc.

\section{Author contributions}

ZW designed and performed research, analyzed data, and wrote the paper. ASD analyzed data and wrote the paper. PD, XW, ZL, AN, YJO, RH, AR, BP, CG, and EU performed experiments and analyzed data. SC designed research. AA designed research, performed experiments, and analyzed data. RA and LEK supervised research. DON, ST, and MS designed and supervised research. ADS conceived and designed the study and wrote the paper. All authors edited and approved the final manuscript.

1. Chondrogianni N, Gonos ES. Structure and function of the ubiquitin-proteasome system: modulation of components. Prog Mol Biol Trans/ Sci 2012; 109: 41-74.

2. Frankland-Searby S, Bhaumik SR. The 26S proteasome complex: an attractive target for cancer therapy. Biochim Biophys Acta 2012; 1825: 64-76.

3. da Fonseca PC, Morris EP. Structure of the human $26 \mathrm{~S}$ proteasome: subunit radial displacements open the gate into the proteolytic core. J Biol Chem 2008; 283: 23305-23314.

4. da Fonseca PC, He J, Morris EP. Molecular model of the human $26 \mathrm{~S}$ proteasome. Mol Cell 2012; 46: 54-66.

5. Ehlinger A, Walters KJ. Structural insights into proteasome activation by the $19 \mathrm{~S}$ regulatory particle. Biochemistry 2013; 52: 3618-3628.

6. Groll M, Ditzel L, Lowe J, Stock D, Bochtler M, Bartunik HD et al. Structure of $20 \mathrm{~S}$ proteasome from yeast at 2.4 A resolution. Nature 1997; 386: 463-471.

7. Heinemeyer W, Fischer M, Krimmer T, Stachon U, Wolf DH. The active sites of the eukaryotic $20 \mathrm{~S}$ proteasome and their involvement in subunit precursor processing. J Biol Chem 1997; 272: 25200-25209.

8. Obeng EA, Carlson LM, Gutman DM, Harrington Jr WJ, Lee KP, Boise LH. Proteasome inhibitors induce a terminal unfolded protein response in multiple myeloma cells. Blood 2006; 107: 4907-4916

9. Adams J, Palombella VJ, Sausville EA, Johnson J, Destree A, Lazarus DD et al. Proteasome inhibitors: a novel class of potent and effective antitumor agents. Cancer Res 1999; 59: 2615-2622.

10. Teicher BA, Ara G, Herbst R, Palombella VJ, Adams J. The proteasome inhibitor PS-341 in cancer therapy. Clin Cancer Res 1999; 5: 2638-2645. 
11. Orlowski RZ, Eswara JR, Lafond-Walker A, Grever MR, Orlowski M, Dang CV. Tumor growth inhibition induced in a murine model of human Burkitt's lymphoma by a proteasome inhibitor. Cancer Res 1998; 58: 4342-4348.

12. Masdehors $\mathrm{P}$, Omura S, Merle-Beral H, Mentz F, Cosset JM, Dumont J et al. Increased sensitivity of CLL-derived lymphocytes to apoptotic death activation by the proteasomespecific inhibitor lactacystin. Br J Haematol 1999; 105: 752-757.

13. Meister S, Schubert U, Neubert K, Herrmann K, Burger R, Gramatzki M et al. Extensive immunoglobulin production sensitizes myeloma cells for proteasome inhibition. Cancer Res 2007; 67: 1783-1792.

14. Jakob C, Egerer K, Liebisch P, Turkmen S, Zavrski I, Kuckelkorn U et al. Circulating proteasome levels are an independent prognostic factor for survival in multiple myeloma. Blood 2007; 109: 2100-2105.

15. Wada M, Kosaka M, Saito S, Sano T, Tanaka K, Ichihara A. Serum concentration and localization in tumor cells of proteasomes in patients with hematologic malignancy and their pathophysiologic significance. J Lab Clin Med 1993; 121: 215-223.

16. Demo SD, Kirk CJ, Aujay MA, Buchholz TJ, Dajee M, Ho MN et al. Antitumor activity of PR-171, a novel irreversible inhibitor of the proteasome. Cancer Res 2007; 67: 6383-6391.

17. Ruschak AM, Slassi M, Kay LE, Schimmer AD. Novel proteasome inhibitors to overcome bortezomib resistance. J Natl Cancer Inst 2011; 103: 1007-1017.

18. Lonial S, Boise LH. Current advances in novel proteasome inhibitor-based approaches to the treatment of relapsed/refractory multiple myeloma. Oncology 2011; 25: 25-31.

19. Kuhn DJ, Chen Q, Voorhees PM, Strader JS, Shenk KD, Sun CM et al. Potent activity of carfilzomib, a novel, irreversible inhibitor of the ubiquitin-proteasome pathway, against preclinical models of multiple myeloma. Blood 2007; 110: 3281-3290.

20. Chauhan D, Singh AV, Aujay M, Kirk CJ, Bandi M, Ciccarelli B et al. A novel orally active proteasome inhibitor ONX 0912 triggers in vitro and in vivo cytotoxicity in multiple myeloma. Blood 2010; 116: 4906-4915.

21. Zhou HJ, Aujay MA, Bennett MK, Dajee M, Demo SD, Fang Y et al. Design and synthesis of an orally bioavailable and selective peptide epoxyketone proteasome inhibitor (PR-047). J Med Chem 2009; 52: 3028-3038.

22. Kim PK, Annis MG, Dlugosz PJ, Leber B, Andrews DW. During apoptosis Bcl-2 changes membrane topology at both the endoplasmic reticulum and mitochondria. Mol Cell 2004; 14: 523-529

23. Papadopoulos K, Mendelson D, Tolcher A, Patnaik A, Burris H, Rasco D et al. A phase I, open-label, dose-escalation study of the novel oral proteasome inhibitor (PI) ONX 0912 in patients with advanced refractory or recurrent solid tumors. J Clin Oncol 2011; 29, abstract 3075 .
24. Savona M, Berdeja J, Lee S, Wong H, Lee J, Gillenwater $\mathrm{H}$ et al. A phase lb dose-escalation study of split-dose oprozomib (ONX0912) in patients with hematologic malignancies. Blood 2012; 120, abstract 203.

25. Richardson PG, Briemberg H, Jagannath S, Wen PY, Barlogie B, Berenson J et al. Frequency, characteristics, and reversibility of peripheral neuropathy during treatment of advanced multiple myeloma with bortezomib. J Clin Oncol 2006; 24: 3113-3120.

26. Lonial S, Waller EK, Richardson PG, Jagannath S, Orlowski RZ, Giver CR et al. Risk factors and kinetics of thrombocytopenia associated with bortezomib for relapsed, refractory multiple myeloma. Blood 2005; 106: 3777-3784.

27. Siegel D, Martin T, Nooka A, Harvey RD, Vij R, Niesvizky R et al. Integrated safety profile of single-agent carfilzomib: experience from 526 patients enrolled in 4 phase II clinical studies. Haematologica 2013; 98: 1753-1761.

28. Swinson J. Fluorine - a vital element in the medicine chest. PharmaChem 2005: 5/6: $1-4$

29. Yang J, Wang Z, Fang $\mathrm{Y}$, Jiang J, Zhao F, Wong $\mathrm{H}$ et al. Pharmacokinetics, pharmacodynamics, metabolism, distribution, and excretion of carfilzomib in rats. Drug Metab Dispos 2011; 39: 1873-1882.

30. Papadopoulos K, Siegel D, Singhal S, Infante J, Sausville E, Gordon M et al. Phase Ib evaluation of the safety and efficacy of a 30 minute iv infusion of carfilzomib in patients with relapsed and/or refractory multiple myeloma. Blood 2010; 116, abstract 3024.

31. Niewerth D, Kaspers GJ, Assaraf YG, van Meerloo J, Kirk CJ, Anderl J et al. Interferongamma-induced upregulation of immunoproteasome subunit assembly overcomes bortezomib resistance in human hematological cell lines. J Hematol Oncol 2014; 7: 7.

32. Niewerth D, Franke NE, Jansen G, Assaraf YG, van Meerloo J, Kirk CJ et al. Higher ratio immune versus constitutive proteasome level as novel indicator of sensitivity of pediatric acute leukemia cells to proteasome inhibitors. Haematologica 2013; 98: 1896-1904.

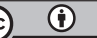

Cell Death and Disease is an open-access journal published by Nature Publishing Group. This work is licensed under a Creative Commons Attribution 4.0 International License. The images or other third party material in this article are included in the article's Creative Commons license, unless indicated otherwise in the credit line; if the material is not included under the Creative Commons license, users will need to obtain permission from the license holder to reproduce the material. To view a copy of this license, visit http://creativecommons.org/licenses/by/4.0/

Supplementary Information accompanies this paper on Cell Death and Disease website (http://www.nature.com/cddis) 